\title{
STRATEGI PEMBELAJARAN PENDIDIKAN AGAMA ISLAM BAGI ANAK TUNAGRAHITA
}

\author{
Fauzul Andim, A.Saiful Aziz, A.Munib \\ mail to: abimanyu.blora5784@gmail.com jhonsaifulaziz@gmail.com \\ masmunib.99@gmail.com \\ SLB Negeri Ungaran, Universitas Wahid Hasyim Semarang
}

\begin{abstract}
Education is the right of all citizens regardless of origin, caste or physical condition of a person, including children with disabilities. As mandated in the Constitution Number 20 of 2003 concerning the National Education System in article 5 paragraphs 1 and 2 it is stated that "Every citizen has the same right to obtain quality education and "Every citizen who has physical, mental, intellectual and or social workers have the right to special education" (UU Sisdiknas 2003). Therefore, Islamic religious education must also be given to children with special needs, one of which is mentally retarded children, of course in the learning process using different learning strategies from the learning strategies applied to formal school students.
\end{abstract}

\section{Keywords: Mental retardation, Learning Strategy}

\begin{abstract}
Abstrak
Pendidikan sebagai hak seluruh warga negara tanpa membedakan asal-usul, kasta maupun keadaan fisik seseorang, termasuk anak-anak yang memiliki kecacatan. Sebagaimana di amanatkan dalam UUD Nomor 20 Tahun 2003 tentang Sistem Pendidikan Nasional pada pasal 5 ayat 1 dan 2 dinyatakan bahwa "Setiap warga negara mempunyai hak yang sama untuk memperoleh pendidikan yang bermutu dan "Setiap warga Negara yang memiliki kelainan fisik, mental, intelektual dan atau sosial berhak memperoleh pendidikan khusus" (UU Sisdiknas 2003). Oleh sebab itulah pendidikan agama Islam juga harus diberikan kepada anak berkebutuhan khusus salah satunya adalah anak Tunagrahita, tentunya dalam proses pembelajarannya menggunakan strategi pembelajaran yang berbeda dengan strategi pembelajaran yang diterapkan pada siswa sekolah formal.
\end{abstract}

Kata kunci: Tunagrahita, Strategi Pembelajaran

\section{A. Pendahuluan.}

Haruskah anak yang memiliki kebutuhan khusus mendapatkan pendidikan agama? Jawabannya tentu saja ya. Karena setiap manusia yang terlahir mempunyai hak dan kewajiban yang sama, dan kita menyadari bahwasanya setiap anak yang terlahir pastilah ada yang memiliki sebuah kelebihan dan juga 
kekurangan. Meskipun demikian, dalam kehidupan sosial dalam masyarakat banyak anggapan yang muncul bahwa anak yang dilahirkan karena suatu kelainan mempunyai status yang lebih rendah, sering kali anak tersebut dijauhi dan bahkan mereka dikucilkan dari kehidupan bermasyarakat pada umumnya. Realita tersebut diperparah dengan adanya sebagian orang tua yang memiliki anak yang memiliki kelainan justru menjauhkan anaknya dari teman sebayanya. Hal tersebut biasanya lebih disebabkan karena para orang tua merasa malu dengan keadaan yang dimiliki anaknya. Padahal meskipun seorang anak memiliki kekurangan atau keterbatasan mereka tetap harus mendapatkan pendidikan yang layak.

Pendidikan merupakan upaya sistematis untuk mengembangkan potensi peserta didik baik nilai, moral dan keyakinan untuk kehidupan masa kini dan mendatang. ${ }^{1}$ Upaya tersebut harus dilakukan dengan penuh kesadaran dan perencanaan yang baik tujuan yang diharapkan bisa tercapai. Karena dalam pendidikan sendiri berisikan rencana dan tujuan untuk dapat menciptakan generasi unggul dan baik. Pendidikan merupakan salah satu sarana paling ampuh untuk membentuk seseorang menjadi pribadi yang unggul baik dari sisi intelektual, mental dan moral. Salah satu tujuan pendidikan dalam membentuk karakter yang baik merupakan prioritas utama. ${ }^{2}$ Karena "Character education aimed at the inculcation of specific virtues, depends heavily on the identification and discription of exemplars". 3 Pernyataan tersebut menunjukkan bahwa pendidikan memiliki tujuan mulia untuk mengajarkan nilai-nilai yang baik.

Jadi jelaslah bahwa pendidikan merupakan wahana utama untuk menumbuhkembangkan segala potensi seseorang ke arah yang lebih baik, karena "pendidikan

${ }^{1}$ Puji Dwi Darmoko, "Peran Pendidikan Seni dalam Membentuk Karakter Bangsa", Jurnal Ilmiah Madaniyah, III, Vol. 1, 2012 , hlm. 22.

${ }^{2}$ Yasmaruddin Bardansyah, "Pembentukan Karakter (Studi Terhadap Mahasiswa UIN Suska Riau dalam Membentuk Karakter Islami), Al-Fikra, Jurnal Ilmiah Keislaman, Vol. 8, No.2, 2009, hlm. 246.

${ }^{3}$ Nel Noddings, Philosophy of Education, (United States of America: Westview Press, 1998), hlm. 150. 
merupakan pilar bangsa". ${ }^{4}$ i sinilah pentingnya pendidikan untuk diberikan sedini mungkin kepada generasi penerus bangsa khususnya bagi para pelajar tak terkecuali bagi pelajar (anak) yang memiliki kebutuhan khusus.

Berdasarkan penelitian yang ada jumlah mereka di Indonesia telah mencapai sekitar 6,6 juta orang atau $3 \%$ dari jumlah penduduk sekitar 220 juta jiwa (ANTARA, 2007). Jumlah yang sangat fantastis dan memerlukan perhatian yang luar biasa dari dunia pendidikan untuk mencermati kembali, apakah pelayanan pendidikan dan masyarakat Indonesia telah berupaya semaksimal mungkin menjadi lingkungan serta masyarakat yang ramah serta menerima dengan terbuka anak-anak dengan keterbatasan mental tersebut.

Dibutuhkan strategi yang khusus dalam pelajaran pendidikan agama Islam agar bisa diterima dengan baik oleh peserta didik, baik itu peserta didik yang mengenyam pendidikan di sekolah reguler maupun peserta didik yang memiliki kebutuhan khusus (ABK) yang bersekolah di sekolah luar biasa (SLB). Karena bagaimanapun juga SLB merupakan salah lembaga pendidikan bagi mereka yang memiliki kebutuhan khusus yang di dalam kurikulumnya juga terdapat mata pelajaran pendidikan agama Islam.

Strategi pembelajaran tak terkecuali dalam pembelajaran pendidikan agama Islam (PAI) yang di desain oleh seorang pendidik akan menjadi sebuah kunci keberhasilan pembelajaran tersebut. Sebagaimana yang dijelaskan oleh Sudjana bahwa tiga variabel dalam pendidikan yaitu kurikulum, pendidikan dan proses pembelajaran akan berjalan dengan baik manakala di dukung dengan strategi pembelajaran yang baik pula. ${ }^{5}$ Oleh sebab itulah strategi pendidikan agama Islam bagi anak berkebutuhan khusus memang sangat penting untuk dimiliki oleh guru pendidikan agama Islam.

Sekolah Luar Biasa (SLB) merupakan lembaga yang khusus mendidik anak berkebutuhan khusus. Sebagai lembaga pendidikan formal di bawah naungan

${ }^{4}$ Abdul Jalil, "Karakter Pendidikan Untuk Membentuk Pendidikan Karakter (Studi Kasus Mahad Qudsiyyah Menara Kudus)", Jurnal Nadwa Fakultas Tarbiyah IAIN Walisongo Semarang, Vol. 6, No. 2, 2012, hlm. 240.

${ }^{5}$ Nana Sudjana, Dasar-Dasar Proses Belajar Mengajar, (Bandung: Sinar Baru Algensindo, 2005), hlm. 1. 
Kementerian Pendidikan dan Kebudayaan tentunya kurikulum yang dijalankan adalah kurikulum yang di dalamnya terdapat mata pelajaran pendidikan agama Islam. Oleh sebab itulah untuk mengembangan potensi yang dimiliki oleh anak berkebutuhan khusus melalui pendidikan Agama Islam bisa terlaksana. Harapannya dengan dibekali pengetahuan pendidikan agama Islam anak berkebutuhan khusus bisa mengamalkan ajaran agamanya dengan penuh rasa tanggungjawab.

\section{B. PEMBAHASAN}

\section{Pengertian Anak Tunagrahita.}

Istilah Tunagrahita berasal dari bahasa Sansekerta yaitu tuna berarti merugi dan grahita arinya pikiran. ${ }^{6}$ Dalam bahasa yang sederhana bisa diartikan sebagai keterbatasan dalam berpikir. Tunagrahita adalah istilah yang digunakan untuk menyebutkan anak yang mempunyai "keadaan dengan intelegensia yang kurang sejak masa perkembangan (sejak lahir atau sejak masa kanak-kanak)” (Wiyani, 2014: 99). ${ }^{7}$ Oleh sebab itulah anak tunagrahita sering mengalami kelemahan dalam berpikir. Pengertian lain menyebut tunagrahita adalah "istilah untuk menyebut anak atau orang yang memiliki kemampuan di bawah rata-rata atau biasa disebut dengan retardasi mental" ${ }^{8}$ Selain itu, tunagrahita adalah "kelainan yang meliputi fungsi intelektual umum dibawah rata-rata (Sub avarage) yaitu IQ 84 ke bawah sesuai tes". 9

Tunagrahita adalah istilah yang digunakan untuk menyebut anak yang mempunyai kemampuan intelektual di bawah rata-rata. Dalam bahasa lainnya tuna grahita disebut retardasi mental yaitu "suatu kondisi ketika tingkat

${ }^{6}$ Kemis \& Ati Rosnawati, Pendidikan Anak Berkebutuhan Khusus Tunagrahita, (Jakarta: Luxima Metro Media, 2013), hlm. 9.

${ }^{7}$ Novan Ardy Wiyani, Buku Ajar Penanganan Anak Usia Dini Berkebutuhan Khusus, (Yogyakarta: Ar-Ruzz Media, 2014), hlm. 99.

${ }^{8}$ Aqila Smart, Anak Cacat Bukan Kiamat, Metode Pembelajaran \& Terapi untuk Anak Berkebutuhan Khusus, (Yokyakarta: Katahati, 2010), hlm. 49.

${ }^{9}$ Ardhi Wijaya, Teknik Mengajar Siswa Tunagrahita (Disabilitas Intelegensia-Gangguan Intelektual, (Yogyakarta: Imperium, 2013), hlm. 24. 
kecerdasan anak berada di bawah rata-rata, intelegensinya sekitar 50-70"10 Berdasarkan penjelasan di atas dapat disimpulkan bahwa yang dimaksud dengan anak tunagrahita adalah anak yang memiliki problem belajar karena memimiliki kecerdasan dibawah rata-rata, mengalami kesulitan dalam berkomunikasi dan sosial yang semua itu bisa disebabkan adanya keterbatasan intelegensi, mental, emosi, sosial, dan juga fisik. Oleh sebab itulah mereka membutuhkan layanan pendidikan khusus dengan perlakuan khusus pula.

Faktor yang bisa menyebabkan terjadinya tunagrahita menurit adalah:
a. Faktor keturunan (anomali genetic atau kelainan kromosom).
b. Gangguan metobolisme gizi.
c. Infeksi dan keracunan (saat kehamilan).
d. Trauma dan zat radioaktif.
e. Masalah kelahiran.
f. Serta faktor lingkungan (sosial dan budaya). ${ }^{11}$

Sementara itu Hain dan Harris (1996) dalam Wijayamenyebutkan bahwa yang menjadi penyebab tunagrahita adalah:
a. Anomali dalam kromosom atau gen (misal sindrom down, sindrom Fragile X).
b. Kelahiran prematur ( terjadi kekusakan otak akibat kekurangan oksigen).
c. Masalah kehamilam (terkena rubella, campak jerman, efek obat dan alkohol).
d. Penyakit (miningitis atau campak).
e. Cedera/ kecelakaan (cidera otak)
f. Lingkungan (trauma dan lain sebagainya). ${ }^{12}$

\section{Strategi Pembelajaran Pendidikan Agama Islam Bagi ABK Tunagrahita}

\section{a. Ruang Lingkup Pendidikan Agama Islam Anak Tunagrahita}

Pendidikan Agama dimaksudkan untuk membentuk peserta didik menjadi manusia yang beriman dan bertakwa kepada Tuhan Yang Maha Esa dan berakhlak mulia serta peningkatan potensi spiritual. Akhlak mulia mencakup etika, budi pekerti, dan moral sebagai perwujudan dari

\footnotetext{
${ }^{10}$ Nini Subini, Mengatasi Kesulitan Belajar Pada Anak, (Yogyakarta: Javalitera, 2011), hlm. 45 .

${ }^{11}$ Nunung Apriyanto, Seluk-Beluk Tuna Grahita \& Strategi Pembelajarannya, hlm. 3947.

${ }^{12}$ Ardhi Wijaya, Teknik Mengajar Siswa Tunagrahita, hlm. 24-25.
} 
pendidikan Agama. Peningkatan potensi spiritual mencakup pengenalan, pemahaman, dan penanaman nilai-nilai keagamaan, serta pengamalan nilai-nilai tersebut dalam kehidupan individual ataupun kolektif kemasyarakatan. Peningkatan potensi spritual tersebut pada akhirnya bertujuan pada optimalisasi berbagai potensi yang dimiliki manusia yang aktualisasinya mencerminkan harkat dan martabatnya sebagai makhluk Tuhan.

Pendidikan agama Islam diajarkan mengikuti tuntunan bahwa agama diberikan untuk menghasilkan manusia yang bertakwa kepada Allah SWT dan berakhlak mulia. "Upaya mewujudkan manusia yang beriman dan bartakwa kepada tuhan yang maha esa dan berakhlak mulia tidak akan tercapai apabila mengabaikan peran pendidikan agama di sekolah" ${ }^{13}$

Sebagaimana ditegaskan dalam Undang-Undang Nomor 20 Tahun 2003 tentang Sistem Pendidikan Nasional terutama pasal 5 ayat (2) dijelaskan bahwa "warga negara yang memiliki kelainan fisik, emosional, mental, intelektual, dan/ atau sosial berhak memeroleh pendidikan khusus". ${ }^{14}$ Artinya bahwa pendidikan agama Islam adalah salah satu matapelajaran wajib yang harus diajarkan kepada anak berkebutuhan khusus, terutama anak tunagrahita.

Hal tersebut dikarenakan "pendidikan agama sangat penting dalam kehidupan sehari-hari, khususnya bagi umat Islam". ${ }^{15}$ Hal tersebut sesuai dengan apa yang termaktub dalam UU Sisdiknas bahwa "pendidikan agama dimaksudkan untuk membentuk peserta didik menjadi manusia

\footnotetext{
${ }^{13}$ Magdalena, "Pendidikan Agama Islam di Sekolah Umum", Taallum, Jurnal Pendidikan Islam, Vol. 01, No. 02, 2013, hlm. 131.

${ }^{14}$ Ratih Putri Pratiwi \& Afin Murtiningsih, Kiat Sukses Mengasuh Anak Berkebutuhan Khusus, Yogyakarta: Ar-Ruzz Media, 2013), hlm. 14.

${ }^{15}$ Nurul Azizah, "Peran Pendidikan Agama Islam dalam Mewujudkan Keadilan dan Perdamaian di Indonesia”, Cendikia, Jurnal Pendidikan Islam, Vol.11, No. 2, 2013, hlm. 198.
} 
yang beriman dan bertakwa kepada Tuhan Yang Maha Esa dan berakhlak mulia serta peningkatan potensi spiritual". ${ }^{16}$

Sagala menjelaskan bahwa pendidikan dimaknai sebagai proses mengubah tingkah laku anak didik agar menjadi manusia dewasa yang mampu hidup mandiri dan sebagai anggota masyarakat dalam lingkungan alam sekitar dimana individu itu berada. Pendidikan tidak hanya mencakup pengembangan intelektualitas saja, akan tetapi lebih ditekankan pada proses pembinaan kepribadian anak didik secara menyeluruh sehingga anak menjadi lebih dewasa.

Sesuai dengan Standar Kompetensi dan Kompetensi Dasar dari Departemen Pendidikan Nasional untuk Sekolah Menengah Pertama Luar Biasa pendidikan agama Islam diberikan dengan tujuan untuk: "Menumbuhkembangkan akidah melalui pemberian, pemupukan, dan pengembangan pengetahuan, penghayatan, pengamalan, pembiasaan, serta pengalaman peserta didik tentang agama Islam sehingga menjadi manusia muslim yang terus berkembang keimanan dan ketakwaan kepada Allah SWT, serta mewujudkan manusia Indonesia berakhlak mulia yaitu manusia yang produktif, jujur, adil, etis, berdisiplin, bertoleransi (tasamuh), serta menjaga harmoni secara personal dan sosial" ${ }^{17}$

Sementara itu aspek-aspek yang diajarkan kepada anak berkebutuhan khusus meliputi mata pelajaran al Quran dan Hadits, aqidah, akhlak, fikih serta tarikh dan hadlarah (sejarah). Selain itu pendidikan agama Islam yang diberikan kepada anak berkebutuhan khusus juga senantiasa menekankan kepada keseimbangan, keselarasan dan keserasian hubungan manusia dengan Allah SWT (hablum minallah), hubungan dengan manusia (hablum min an naas), dan hubungan dengan alam sekitar (hablum minal alam).

Proses pembelajaran dalam PAI selalu memperhatikan perbedaan individu (farq al-fard \}iyyah) peserta didik serta menghormati harkat,

${ }^{16}$ Departeman Pendidikan Nasional, "Standar Kompetensi dan Kompetensi Dasar Sekolah Menengah Pertama Luar Biasa Tuna Rungu (SMPLB-B)", (Jakarta: Dirjen Manajemen DikDasMen Direktorat Pembinaan Luar Biasa, 2006), hlm. 3.

${ }^{17}$ Departeman Pendidikan Nasional, "Standar Kompetensi dan Kompetensi Dasar Sekolah Menengah Pertama Luar Biasa Tuna Rungu (SMPLB-B)”, hlm. 4. 
martabat dan kebebasan berfikir mengeluarkan pendapat pendiriannya, sehingga bagi peserta didik belajar merupakan hal yang menyenangkan dan sekaligus mendorong kepribadiannya berkembang secara optimal, sedangkan bagi guru, proses pembelajaran merupakan kewajiban yang bernilai ibadah yang dipertanggungjawabkan di hadapan Allah. ${ }^{18}$

Sesuai arahan dari Departemen Pendidikan Nasional (2006) untuk Sekolah Menengah Pertama Luar Biasa pendidikan agama Islam memiliki ciri diantaranya adalah:

a. lebih menitikberatkan pencapaian kompetensi secara utuh selain penguasaan materi;

b. Mengakomodasikan keragaman kebutuhan dan sumber daya pendidikan yang tersedia;

c. Memberikan kebebasan yang lebih luas kepada pendidik di lapangan untuk mengembangkan strategi dan program pembelajaran sesuai dengan kebutuhan dan ketersediaan sumber daya pendidikan.

Strategi khusus dalam pembelajaran agama Islam bagi anak tunagrahita harus memegang prinsip dasar, diantaranya yaitu:

a. Menyederhanakan materi, terutama materi yang sulit diterima oleh peserta didik.

b. Menghindari penyampaian materi pendidikan agama Islam secara abstrak atau teoritis.

c. Penyampaian materi harus kontekstual, praktis, mudah, visual, bertahap, bertahap dan berkesinambungan secara berulang-ulang agar peserta didik dapat menerima dan memahami materi.

d. Lebih menekankan aspek afektif dan psikomorik dari pada aspek kognitif peserta didik.

e. Menggunakan media dan metode yang tepat dalam proses pembelajaran. (Kurikulum SLB N Semarang: 2010).

f. 95.

${ }^{18}$ Ramayulis, Metodologi Pendidikan Agama Islam, (Jakarta : Kalam Mulia, 2005), hlm. 


\section{Prinsip Pembelajaran Pendidikan Agama Islam Anak Tunagrahita}

Salah satu strategi dalam mendidik anak tunagrahita dalam proses pembelajaran pendidikan agama Islam perlu mengembangkan prinsip-prinsip pendekatan secara khusus, yaitu:

a. Prinsip kasih sayang.

Prinsip kasih sayang pada dasarnya menerima mereka apa adanya, dan mengupayakan agar mereka juga dapat menerima keadaan mereka sehingga mereka dapat menjalankan hidup dan kehidupan dengan wajar, seperti layaknya anak-anak normal lainnya. ${ }^{19}$

b. Prinsip layanan individual.

Pelayanan individual dalam rangka mendidik anak berkebutuhan khusus perlu mendapatkan porsi yang lebih besar, sebab setiap anak yang memiliki kebutuhan khusus dalam jenis dan derajat yang sama seringkali memiliki keunikan problematika yang berbeda antara satu dengan yang lainnya. $^{20}$

c. Prinsip kesiapan.

Agar proses pembelajaran dapat berjalan secara maksimal tentu diperlukan kesiapan, khususnya kesiapan peserta didik untuk mendapatkan materi pelajaran yang akan diajarkan. ${ }^{21}$

d. Prinsip keperagaan.

Kelancaran proses pembelajaran pada anak berkebutuhan khusus (tunagrahita) harus senantiasa didukung oleh penggunaan alat peraga sebagai medianya. ${ }^{22}$

e. Prinsip motivasi.

Prinsip motivasi ini lebih menitikberatkan pada cara mengajar dan pemberian evaluasi yang disesuaikan dengan kondisi anak berkebutuhan khusus. $^{23}$

\footnotetext{
${ }^{19}$ Aqila Smart, “Anak Cacat Bukan Kiamat, hlm. 96.

${ }^{20}$ Ibid, hlm. 80.

${ }^{21}$ Ibid, hlm. 78.

${ }^{22}$ Ibid, hlm. 97.
} 
f. Prinsip belajar dan bekerjasama.

Sebagai salah satu dasar mendidik anak berkebutuhan khusus adalah menyadarkan mereka bahwa mereka merupakan bagian dari masyarakat, agar mereka sebagai anggota masyarakat dapat bergaul dengan masayarakat lingkungannya dengan baik, maka mereka harus ditanamkan semangat untuk bekersama dengan orang lain disekitarnya. ${ }^{24}$

g. Prinsip keterampilan.

Keterampilan yang dimaksud dalam pendidikan agama Islam tentu saja terampil dalam bidang agama. ${ }^{25}$ Minimal anak yang berkebutuhan khusus tunagrahita ringan bisa menjalankan ibadah mahdzoh seperti salat, puasa, zakat dalam kehidupan mereka.

h. Prinsip penanaman dan penyempurnaan sikap.

Secara psikis sikap yang dimiliki oleh anak tunagrahita biasanya kurang baik karena sering tidak terkontrol bahkan apa yang mereka lakukan seringkali tidak direncanakan dan konsekuensi dari perilaku yang mereka lakukan jarang dipikirkan. ${ }^{26}$

\section{Metode Pembelajaran Pendidikan Agama Islam Bagi Anak Tunagrahita}

Pendidikan agama Islam sangat penting diberikan kepada anak tunagrahita ringan karena sangat berguna sekali sebagai modal agar mereka bisa bersosialisasi dalam kehidupan bermasyarakat dengan tetap memegang prinsip iman dan takwa. Keberhasilan proses belajar mengajar sangat ditentukan oleh metode apa yang digunakan. Perlu di sadari, bahwa tidak ada satu metode pembelajaran yang unggul untuk semua tujuan dalam semua kondisi. $^{27}$ Metode pembelajaran yang bisa dipilih dan digunakan saat mengajar pendidikan agama Islam adalah bagi anak tunagrahita adalah:

${ }^{23}$ Ibid, hlm. 78

${ }^{24}$ Ibid, hlm. 80

${ }^{25}$ Ibid, hlm. 81 .

${ }^{26}$ Ibid, hlm. 79

${ }^{27}$ H. Hamzah B Uno, Model Pembelajaran, Menciptakan Proses Belajar Mengajar yang Kreatif dan Efektif, (Jakarta: Bumi Aksara, 2011), hlm. 20. 
a. Metode Ceramah

Metode ceramah merupakan metode pembelajaran yang paling banyak digunakan dalam proses pembelajaran. dalam metode ini perhatian hanya terpusat pada pendidik (guru), sehingga dalam proses pembelajaran guru yang aktif sedangkan peserta didik pasif. $^{28}$

b. Metode Tanya Jawab

Pembelajaran pendidikan agama Islam juga bisa dilakukan dengan menggunakan metode tanya jawab. Metode tersebut digunakan dengan orientasi untuk meninjau ulang materi pelajaran yang telah diajarkan pendidik, atau untuk mengembalikan konsentrasi peserta didik. ${ }^{29}$

c. Metode Demonstrasi

Metode demonstrasi adalah metode pembelajaran yang menggunakan peragaan atau praktek untuk memperjelas suatu pengertian atau untuk memperlihatkan bagaimana melakukan sesuatu kepada peserta didik. ${ }^{30}$ Metode ini sangat tepat digunakan saat mengajarkan materi tentang fiqih seperti materi bersuci, salat, maupun haji.

d. Metode Pemberian Tugas

Metode pemberian tugas adalah "suatu cara dalam proses belajarmengajar bilamana guru memberi tugas tertentu dan murid mengerjakannya, kemudian tugas tersebut dipertanggungjawabkan kepada guru". 31

e. Metode driil (Latihan)

Metode latihan digunakan dalam pembelajaran pendidikan agama Islam bertujuan untuk mengetahui sampai mana tingkat penguasaan

\footnotetext{
${ }^{28}$ Zakiah Daradjat, Ilmu Pendidikan Islam, (Jakarta: Bumi Aksara, 2004), hlm. 289.

${ }^{29}$ Martinis Yamin, Profesionalisasi Guru dan Implementasi KTSP, (Jakarta: Gaung Persada Press, 2007), Cet. Ke-2, hlm. 67.

${ }^{30}$ Zakiah Daradjat, "Ilmu Pendidikan Islam”, hlm. 296.

${ }^{31}$ Zakiah Daradjat, Ibid, hlm. 298
} 
pengetahuan dan kecakapan yang dimiliki oleh peserta didik. ${ }^{32}$ Metode latihan biasanya digunakan saat pembelajaran yang sifatnya menulis, contohnya bahasa arab.

f. Metode pembiasaan. Metode ini digunakan untuk mengajarkan hafalan, misal hafalan surat-surat pendek.

\section{Kesimpulan}

Dari berbagai uraian diatas, maka penulis dapat mengambil kesimpulan sebagai berikut:

1. Strategi pembelajaran pendidikan agama Islam bagi anak Tunagrahita dengan menyederhanakan materi, hindari penyampaian materi secara abstrak, penyampaian materi harus (kontekstual, mudah, praktis, visual, bertahap, berkesinambungan dan berulang-ulang), menekankan aspek afektif dan psikomotorik, serta menggunakan media dan metode yang sesuai.

2. Prinsip dasar pembelajaran pendidikan agama Islam bagi anak Tunagrahita menggunakan prinsip kasih sayang, layanan individual, kesiapan, keperagaan, motivasi, belajar dan bekerjasama, keterampilan dan prinsip penanaman dan penyempurnaan sikap.

3. Metode pembelajaran pendidikan agama Islam bagi anak Tunagrahita yang sering digunakan adalah metode ceramah, meode tanya jawab, metode demonstrasi, metode pemberian tugas dan metode driil (latihan) dan metode pembiasaan.

\section{DAFTAR PUSTAKA}

Aqila Smart, Anak Cacat Bukan Kiamat, Metode Pembelajaran \& Terapi untuk Anak Berkebutuhan Khusus, Yokyakarta: Katahati, 2010.

Azizah, Nurul, "Peran Pendidikan Agama Islam dalam Mewujudkan Keadilan dan Perdamaian di Indonesia", Cendikia, Jurnal Pendidikan Islam, Vol.11, No. 2, 2013.

Bardansyah, Yasmaruddin, "Pembentukan Karakter (Studi Terhadap Mahasiswa UIN Suska Riau dalam Membentuk Karakter Islami), Al-Fikra, Jurnal Ilmiah Keislaman, Vol. 8, No.2, 2009.

Daradjat, Zakiah, Ilmu Pendidikan Islam, Jakarta: Bumi Aksara, 2004.

\footnotetext{
${ }^{32}$ Zakiah Daradjat, Ibid, hlm. 302.
} 
Darmoko, Puji Dwi, "Peran Pendidikan Seni dalam Membentuk Karakter Bangsa”, Jurnal Ilmiah Madaniyah, III, Vol. 1, 2012.

Departeman Pendidikan Nasional, "Standar Kompetensi dan Kompetensi Dasar Sekolah Menengah Pertama Luar Biasa Tuna Rungu (SMPLB-B)", Jakarta: Dirjen Manajemen DikDasMen Direktorat Pembinaan Luar Biasa, 2006.

Departeman Pendidikan Nasional, "Standar Kompetensi dan Kompetensi Dasar Sekolah Menengah Pertama Luar Biasa Tuna Rungu (SMPLB-B).

Hamzah B Uno, Model Pembelajaran, Menciptakan Proses Belajar Mengajar yang Kreatif dan Efektif, Jakarta: Bumi Aksara, 2011.

Jalil, Abdul, "Karakter Pendidikan Untuk Membentuk Pendidikan Karakter (Studi Kasus Mahad Qudsiyyah Menara Kudus)", Jurnal Nadwa Fakultas Tarbiyah IAIN Walisongo Semarang, Vol. 6, No. 2, 2012.

Kemis \& Ati Rosnawati, Pendidikan Anak Berkebutuhan Khusus Tunagrahita, Jakarta: Luxima Metro Media, 2013.

Magdalena, "Pendidikan Agama Islam di Sekolah Umum", Taallum, Jurnal Pendidikan Islam, Vol. 01, No. 02, 2013.

Noddings, Nel, Philosophy of Education, United States of America: Westview Press, 1998.

Pratiwi, Ratih Putri \& Afin Murtiningsih, Kiat Sukses Mengasuh Anak Berkebutuhan Khusus, Yogyakarta: Ar-Ruzz Media, 2013.

Ramayulis, Metodologi Pendidikan Agama Islam, Jakarta: Kalam Mulia, 2005.

Subini, Nini, Mengatasi Kesulitan Belajar Pada Anak, Yogyakarta: Javalitera, 2011.

Sudjana, Nana, Dasar-Dasar Proses Belajar Mengajar, Bandung: Sinar Baru Algensindo, 2005.

Wijaya, Ardhi, Teknik Mengajar Siswa Tunagrahita (Disabilitas IntelegensiaGangguan Intelektual, Yogyakarta: Imperium, 2013.

Wiyani, Novan Ardy, Buku Ajar Penanganan Anak Usia Dini Berkebutuhan Khusus, Yogyakarta: Ar-Ruzz Media, 2014.

Yamin, Martinis, Profesionalisasi Guru dan Implementasi KTSP, Jakarta: Gaung Persada Press, 2007. 